\title{
Accounting for differences in income inequality across countries: tax-benefit policy, labour market structure, returns and demographics
}

\author{
Denisa M. Sologon ${ }^{1}$ (D) . Philippe Van Kerm ${ }^{1,2} \cdot{\text { Jinjing } \mathrm{Li}^{3} \cdot \text { Cathal O'Donoghue }}^{4}$
}

Received: 29 March 2018 / Accepted: 9 July 2020 / Published online: 10 October 2020

(C) The Author(s) 2020

\begin{abstract}
This paper presents a framework for studying international differences in the distribution of household income. Integrating micro-econometric and micro-simulation approaches in a decomposition analysis, it quantifies the role of tax-benefit systems, employment and occupational structures, labour and financial market returns, and demographic composition in accounting for differences in income inequality across countries. Building upon EUROMOD (the European tax-benefit calculator) and its harmonised datasets, the model is portable and can be implemented for cross-country comparisons between any participating country. An application to the UK and Ireland-two countries that have much in common while displaying different levels of inequality-shows that differences in tax-benefit rules between the two countries account for over one third of the observed difference in disposable household income inequality. Demographic differences play negligible roles. The Irish tax-benefit system is more redistributive than UK's due to a higher tax progressivity and higher average transfer rates. These are largely attributable to policy parameter differences, but also to differences in pre-tax, pre-transfer income distributions.
\end{abstract}

Keywords Income inequality · Cross-national comparisons · Microsimulation · Tax and transfer policy

\section{Introduction}

Trends in income inequality since the 1980s have been the subject of considerable attention; see for example the comprehensive review of thirty countries experiences in Nolan et al.

Electronic supplementary material The online version of this article (https://doi.org/10.1007/s10888-020-09454-7) contains supplementary material, which is available to authorized users.

Denisa M. Sologon

denisa.sologon@liser.lu

Extended author information available on the last page of the article. 
(2014). Examinations of the driving forces behind cross-national differences in inequality are by comparison less common (Förster and Tóth 2015). Yet, variations in income inequality levels across countries tend to be more striking than changes observed within any rich country in recent years. For example, according to OECD (2011), the biggest increase in the Gini coefficient of income between 1985 and 2008 among 22 OECD countries-a change of 0.07 observed in Sweden and in New Zealand—is only half the difference of 0.13 observed between the Gini coefficients for Denmark and the USA in 2008. Among EU countries, the Gini coefficient of income currently ranges from 0.24 in the Slovak Republic to 0.37 in Bulgaria, Romania or Lithuania (Eurostat 2017), a gap larger than any trends recently observed in the EU.

Even though (Brandolini et al. 2010, p.97) once remarked that "... attempts to model and understand causal factors and explanations for differences in level and trends in income inequality across nations is the ultimate challenge to which researchers on inequality should all aspire", the overwhelming majority of recent research has focused on examination of the determinants of trends in inequality within countries rather than on the sources of cross-country differences in the level of inequality; see for example (Hyslop and Mare 2005; Daly and Valletta 2006; Biewen and Juhasz 2012; Jenkins et al. 2013; Larrimore 2014; Herault and Azpitarte 2015; Brewer and Wren-Lewis 2016; Belfield et al. 2017) to mention only recent studies that examined the distribution of household income. ${ }^{1}$ This paper proposes a generic framework for studying international differences in the distribution of household income and an analysis of the UK and Ireland. Integrating micro-econometric and micro-simulation approaches in a decomposition analysis, the objective is to quantify the contribution of four potential drivers to inequality differences between countries: differences in tax-benefit systems, differences in employment and occupational structures, differences in labour prices and market returns, and differences in demographic composition-four factors identified as part of the grand drivers of inequality in Förster and Tóth $(2015)^{2}$

A body of literature has used cross-country regressions to tease out the importance of various economic and institutional variables on inequality. Aggregate indicators of inequality for a range of countries and years are regressed on macro-level economic, political or institutional variables as potential explanatory factors. Notably, empirically testing the relationship between inequality and GDP - the Kuznets hypothesis-has been central to this literature. But inequality determinants go well beyond economic growth. The comprehensive review of recent studies exploiting cross-country regressions in Förster and Tóth (2015) however leads to the disappointing conclusion that "inconclusiveness prevails for many possible drivers of inequality (...) which can often but not always be traced back to different country samples, time periods, data and methodological specifications" (p.1804).

\footnotetext{
${ }^{1}$ An even larger body of literature has examined the trends in earnings and wage inequality (see, e.g., Atkinson, 2007), while the distribution of wealth has recently received growing attention especially since Piketty (2013).

${ }^{2}$ Of course, factors that drive changes in inequality may also explain why inequality differs across countries, but countries still differ considerably with respect to their tax-benefit systems, labour market and social institutions, market structures, and demographic factors, and with respect to social norms and behaviours, culture and history, etc. Alesina and Glaeser (2005) and Haveman et al. (2011).
} 
Decomposition methods have been the main alternative to cross-country regressions. In their simplest form, inequality decomposition methods determine the contributions of a small number of components-sources of income (Shorrocks 1982; Lerman and Yitzhaki 1985) or partitions of the population (Shorrocks 1980) — which add up to total inequality in a country. This naturally leads to comparisons of the composition of inequality across countries or over time as a way to 'explain' inequality differences (see, e.g., Brewer and Wren-Lewis 2016). This approach is limited to particular inequality measures and makes it difficult to examine multiple factors simultaneously. More recently, flexible decomposition approaches have modelled the full income distribution (rather than specific summary indices) and jointly examine several determinants. Typically, the contribution of a number of factors to the differences in inequality is assessed using (a sequence of) simulated counterfactual distributions of household disposable incomes that would prevail in each country (or time period), if these factors were common to different countries (or years). ${ }^{3}$ This is the approach we follow here. It should be clear that this is not trying to generate the income distribution that would realistically be observed if one was to exogenously change the components of interest and then let households, policy-makers and the economy adjust to the change in the long run. Instead, the magnitude of the model's response to the simulated transformation is used to quantify the relative contribution of each of a number of factors of interest to the aggregate difference between two populations. While this has become a popular approach for examinations of changes in inequality, only few studies have attempted such a decomposition in a cross-country analysis.

We build upon the approach developed in Bourguignon et al.'s (2008) study of the determinants of inequality difference between Brazil and the USA. The procedure relies on a parametric representation of the link between the components of household income (individual earnings and unearned income) and household or individual socio-demographic characteristics, complemented by a non-parametric reweighting technique to account for demographic profiles. This approach extends the ubiquitous Oaxaca-Blinder and JuhnMurphy-Pierce decompositions in two ways: first it deals with the entire income distribution, not just mean earnings, and second it builds a parametric income-generation process based on a system of equations for multiple income sources for the household, not just a parametric earnings process for individual wages. We extend Bourguignon et al. (2008) model in several dimensions. The most important difference is the treatment of taxes and benefits. Unlike Bourguignon et al. (2008), we focus on household disposable income after taxes and transfers and explicitly study how much differences in tax-benefit systems across countries account for inequality differences. This is critical not least because policy design and parameters can be modified by government decisions, unlike demographic factors or labour market structure and returns. To obtain the most realistic contribution of taxes and benefits to household income, we incorporate tax-benefit rules by means of the panEuropean tax-benefit micro-simulation engine EUROMOD (Sutherland and Figari 2013). This allows us to represent accurately the relationship between household characteristics, market incomes (from labour and capital) and taxes and benefits. As we show in the comparison of the UK and Ireland, the tax-benefit policy differences turn out to be the main force behind the higher income inequality observed in the UK. The second main develop-

\footnotetext{
${ }^{3}$ See Fortin et al. (2011) for a review.
} 
ment over (Bourguignon et al. 2008) framework is the examination of endogenous labour supply adjustments in the generation of simulated counterfactual distributions.

Such microeconometric decomposition approaches are sometimes dismissed as being too difficult to construct to be of general use (Cowell and Fiorio 2011). We address this concern by developing a framework that is portable across European countries. The model is constructed on the basis of household survey data that are available in harmonised form in all EU countries. Using cross-country comparable data, the income distribution model has a common specification for each country so as to permit the simulation of counterfactual distributions holding components constant across countries. Also, by exploiting EUROMOD, the heterogeneity of tax-benefit rules is easily incorporated. This means that the model can be used to examine inequality differences across any pairs of European countries using a common analytic framework.

We undertake a comparison of Ireland and the UK. Ireland and UK have always formed a common travel area and labour market, they share a language and border and their Welfare States have evolved contemporaneously, influenced by similar political philosophy principles. Nevertheless there are also sufficient differences to call for examination of the factors that have resulted in different levels of inequality. We examine the year 2007, which is the latest year before the financial crisis hit both countries. The Gini coefficient was 0.28 in Ireland - a relatively low figure by international standards - while it had reached 0.32 in the UK. Our results show that the direct effect of differences in tax-benefit rules between the two countries accounts for roughly half of the observed difference in income inequality. The Irish tax-benefit system is more redistributive than the UK system due to a higher tax progressivity and more generous average transfer rates. These are largely attributable to differences in policy parameters, but also to differences in pre-tax, pre-transfer (market) income distributions.

While decomposition studies are often presented without measures of statistical precision given the potential computational challenges, we provide confidence intervals based on a grouped jackknife approach for effects of the four main drivers (policy, labour market structure, returns and demographics) and find reassuringly narrow confidence intervals.

The paper is organized as follows. Section 2 describes our representation of the "income generation process": we define the components of household income and we outline parametric specifications to capture how these income sources vary with household and individual characteristics. Section 3 proposes four generic "transformations" of income generation processes and shows how these transformations applied to estimates for different countries can be used to account for cross-country inequality differences. Application to the UK-Ireland contrast is presented in Section 4. An extension incorporating potential labour supply responses is developed Section 5. Section 6 concludes. Appendices A and B provide more detailed description of important implementation ingredients.

\section{A Representation of the Household Disposable Income Generation Process}

The core of the analysis is a representation of household incomes on the basis of (i) a set of basic observable individual and household characteristics, (ii) a vector of parameters describing how employment and the receipt and level of income sources vary with those characteristics, and (iii) a vector of household-specific 'residuals' linking predictions from 
model parameters to observed income sources. To fix ideas, consider the common representation of, say, earnings, as $y_{h}=x_{h} \beta+u_{h}$. The three components are (i) $x_{h}$ the household characteristics, (ii) $\beta$ the parameter vector and (iii) $u_{h}$ the household's idiosyncratic residual. Each of the component can contribute to the variance of earnings. In the simplest univariate model $V_{y}=\beta^{2} V_{x}+V_{u}$ with $V_{y}$ the variance of earnings and $V_{x}$ and $V_{u}$ the variance of characteristics and residuals (Juhn et al. 1993). Differences in demographic and education characteristics reflect basic, observable population heterogeneity; parameter vectors capture how much differences in such basic characteristics lead to differences in (various sources of) income; residuals capture the magnitude of income differences between households with identical characteristics. A simple univariate regression model is however too limited to provide a satisfactory representation of total household incomes. Building upon Bourguignon et al. (2008), we therefore develop and estimate a more comprehensive income generation process with multiple equation specifications for detailed sources of income. Simulations are then used to assess the contribution of the various components of the model to overall household income inequality and compare their relative contribution to cross-country differences in inequality.

\subsection{Household disposable income components}

We consider five main components of total household disposable income $y_{h}$, namely (gross) labour incomes, capital incomes, other non-benefit pre-tax incomes (e.g., private pensions, alimonies), public transfers and (minus) direct taxes:

$$
y_{h}=y_{h}^{L}+y_{h}^{K}+y_{h}^{O}+y_{h}^{B}-t_{h} .
$$

One can broadly think of the first three sources as returns to human capital, returns to physical or financial capital, and other private (or market) incomes. The last two reflect the direct intervention of the State through transfers and taxes.

Most of these five sources are themselves aggregates of smaller components of income - notably contributions of individuals to overall household income-which we are going to model separately in order to have a parametric representation that is defined at a fine level of disaggregation. The details of our disaggregation are as follows. Labour income is the sum of employee and self-employment incomes of each household member:

$$
y_{h}^{L}=\sum_{i=1}^{n_{h}} I_{h i}^{l a b}\left(I_{h i}^{e m p} y_{h i}^{e m p}+I_{h i}^{s e} y_{h i}^{s e}\right)
$$

where, in all expressions, $I_{j}^{S}$ refers to a binary indicator equal to 1 if person (or household) $j$ receives any income from source $S$ (and 0 otherwise) whereas $y_{j}^{S}$ refers to the actual amount of income source $S$ received. So $I_{h i}^{l a b}=1-\left(1-I_{h i}^{e m p}\right)\left(1-I_{h i}^{s e}\right)$ identifies whether person $h i$ receives any labour income and $I_{h i}^{e m p}$ and $I_{h i}^{s e}$ identify whether she receives income from salaried employment or from self-employment. (Although the use of binary indicators is not required at this stage, their use will become clear below.) Capital income is the sum of investment income and property income received by each household member:

$$
y_{h}^{K}=\sum_{i=1}^{n_{h}}\left(I_{h i}^{i n v} y_{h i}^{i n v}+I_{h i}^{\text {prop }} y_{h i}^{\text {prop }}\right) .
$$

The 'other incomes' component includes private pension payments and a catch-all measure that aggregates all non-benefit individual incomes that are not included in labour and capital 
incomes (mainly private transfers such as alimonies),

$$
y_{h}^{O}=\sum_{i=1}^{n_{h}}\left(I_{h i}^{\text {pripen }} y_{h i}^{\text {pripen }}+I_{h i}^{\text {other }} y_{h i}^{\text {other }}\right) .
$$

The sum $y_{h}^{L}+y_{h}^{K}+y_{h}^{O}$ is the total pre-transfer, pre-tax income of household $h$ (or what we will also call 'market income' of household $h$ ). We then add public transfers $y_{h}^{B}$ and deduct taxes $t_{h}$ to arrive at disposable income. Public transfers are composed of a range of individual replacement incomes (pension, survivor pension, disability, sickness and unemployment benefits), of household-level means-tested social assistance (including housing support) and of universal transfers to which household $h$ is eligible (including child support). For simplicity we combinethree broad household-level aggregates-public pensions, means-tested benefits and non-means-tested benefits:

$$
y_{h}^{B}=y_{h}^{\text {pens }}+y_{h}^{m t b}+y_{h}^{n m t b} .
$$

The fifth component is the level of direct taxes and social contributions paid by household $h$. Direct taxes and social contributions are determined by the tax schedule in place as a function of the vector of gross incomes and household characteristics and composition:

$$
t_{h}=\operatorname{tax}_{h}+\sum_{i=1}^{n_{h}} s s c_{h i} .
$$

\subsection{Parametric Mappings}

Having determined five main sources of household income and their components, we specify parametric relationships between observed household characteristics and each component. We define the parametric relationships at the level of the most disaggregate income components described above. For the sake of brevity, we focus here on the framework and only summarize the sets of key parameters. The full specification details are described in Appendix A. ${ }^{4}$ In a nutshell, we use reduced-form log-linear specifications for most pre-tax income components (in the spirit of Juhn et al. (1993)), with a few important exceptions. First, we distinguish the probability of receipt of an income source and the level of income conditional on receipt in separate equations. Second, we capture the role of cross-country differences in the occupational and industrial structure of employment, as Bourguignon et al. (2008) do, by specifying equations for occupations and sector of employment and conditioning labour income on these variables. Third, we use a flexible parametric distributional regression for wages instead of the log-linear specification. Fourth, we combine parametric specifications with a tax-benefit micro-simulation engine, EUROMOD, for the determination of taxes and benefits.

Taken together, parametric mappings provide us with the following representation of the income generation process. The three sources of market income are

where

$$
\begin{gathered}
y_{h}^{L}=g^{L}\left(x_{h}, \xi^{L}, \Upsilon^{L}\right) \\
y_{h}^{K}=g^{K}\left(x_{h}, \xi^{K}, \Upsilon^{K}\right) \\
y_{h}^{O}=g^{O}\left(x_{h}, \xi^{O}, \Upsilon^{O}\right)
\end{gathered}
$$

\footnotetext{
${ }^{4}$ See also an earlier version of this paper (Sologon et al. 2018).
} 
- the functions $g^{L}, g^{K}$ and $g^{O}$ generically denote the functional forms of the parametric specifications; they are composed of a set of hierarchically structured equations, most of them linear in parameters, detailed in Appendix A;

- $\quad x_{h}$ is a vector of demographic characteristics of household $h$ that includes the age and number of children in the household, and the age, education level, marital status and citizenship of all adult members;

$$
\begin{aligned}
\xi^{L}= & \left(\gamma^{\text {lab }}, \gamma^{\text {emp }}, \gamma^{\text {hrs }}, \delta^{\text {pub }}, \delta^{\text {occ }}, \delta^{\text {ind }},\left(\beta^{\text {se }}, \sigma^{\text {se }}\right),\left(\beta^{\text {a,emp }}, \beta^{\text {bemp }}, \beta^{q, e m p}\right),\right. \\
\xi^{K}= & \left(\gamma^{\text {inv }}, \gamma^{\text {prop }},\left(\beta^{\text {inv }}, \sigma^{\text {inv }}\right),\left(\beta^{\text {prop }}, \sigma^{\text {prop }}\right), \text { and } \xi^{O}=\left(\gamma^{\text {pripen }}, \gamma^{\text {other }},\left(\beta^{\text {pripen }},\right.\right.\right. \\
& \left.\left.\sigma^{\text {pripen }}\right),\left(\beta^{\text {other }}, \sigma^{\text {other }}\right)\right)
\end{aligned}
$$

are vectors of coefficients of the parametric specifications (detailed in Appendix ??) that map demographic characteristics on the different income sources through participation, employment and income equations; and

$$
\begin{aligned}
\Upsilon^{L} & =\left(\epsilon_{h i}^{l a b}, \epsilon_{h i}^{\text {emp }}, \epsilon_{h i}^{k, o c c}, \epsilon_{h i}^{k, i n d}, \epsilon_{h i}^{\text {pub }}, \epsilon_{h i}^{\text {hrs }}, v_{h i}^{\text {se }}, v_{h i}^{\text {emp }}\right), \\
\Upsilon^{K} & =\left(\epsilon_{h}^{i n v}, \epsilon_{h}^{\text {prop }}, v_{h}^{\text {inv }}, v_{h}^{\text {prop }}\right), \text { and } \Upsilon^{O}=\left(\epsilon_{h}^{\text {pripen }}, \epsilon_{h}^{\text {other }}, v_{h}^{\text {pripen }}, v_{h}^{\text {other }}\right)
\end{aligned}
$$

are vectors of normalised residuals from each of the equations, where the residuals are scaled to have unit variance in the population (the (variance of residuals is treated as a parameter of the specifications).

Public transfers and taxes are handled differently. Since taxes and many transfers are determined by the level of market incomes, alongside household characteristics, they cannot be calculated and simulated independently of market income. We derive taxes and a range of benefits on the basis of a tax-benefit calculator that estimates the amount of benefits received and income tax paid (or, at least, due) as a function of market income sources, household characteristics and a number of variables which may influence the benefit eligibility and tax liabilities according to the rules in place. Many such calculators exist, but for cross-country comparative analysis, it is useful to rely on an engine that models taxes and benefits in a consistent way across countries. Harmonised taxes and benefit calculations can be taken from EUROMOD, a large scale pan-European tax-benefit static micro-simulation engine (Sutherland and Figari 2013). This large-scale income calculator incorporates the tax-benefit schemes of the majority of European countries and allows computation of predicted household disposable income, on the basis of pre-tax, pre-benefit incomes, employment and other household characteristics. EUROMOD simulates the policy components of household disposable income (direct taxes and a wide range of cash transfers to households: income and property taxes, social insurance contributions, family benefits, housing benefits, social assistance, and, where relevant other income-related benefits) and also employer social insurance contributions and minimum wage rules (Figari et al. 2015). We can therefore express the last two income components as

$$
\begin{aligned}
y_{h}^{B} & =g^{B}\left(x_{h}, y_{h}^{L}, y_{h}^{K}, y_{h}^{O}, \xi^{B}, \Upsilon^{B}\right) \\
t_{h} & =g^{T}\left(x_{h}, y_{h}^{L}, y_{h}^{K}, y_{h}^{O}, y_{h}^{B}, \xi^{T}\right)
\end{aligned}
$$

where the functions $g^{B}$ and $g^{T}$ are, essentially, the EUROMOD representations of the tax-benefit rules with policy parameters prameters denoted $\xi^{B}$ and $\xi^{T}$. Not all benefits are calculated in EUROMOD however. Pensions, notably, depend on past contributions and cannot be calculated based on contemporaneous income and household characteristics information. Such benefits are therefore treated like market income sources and specified separately on the basis of a log-linear model whose coefficients are subsumed in the parameter vector $\xi^{B}$ and residuals in $\Upsilon^{B}$ (see Appendix A.1). 
A (joint) distribution of household characteristics and normalised residual terms with Eqs. 7-11 fully characterise a distribution of household disposable incomes. Having defined a representation of the whole household income generation process in terms of household characteristics, model parameters, and vectors of residuals, we now define a number of transformations which, applied to this income generation process, allow us to generate counterfactual constructs.

\section{Counterfactual Distributions and the Decomposition of Cross-Country Inequality Differences}

It is convenient to rewrite our representation of the income generation process as a generic non-separable model

$$
Y=m(X, \Upsilon)
$$

where $Y$ is income, $X$ is the vector of 'exogenous' individual and household characteristics and $\Upsilon$ is a vector of scaled residual (or unobserved heterogeneity) terms (Matzkin 2003; Rothe 2010). The function $m$ describes the relationship between household characteristics and income and the heterogeneity in $Y$ that is not 'explained' by $X$. The derivative of $m$ with respect to its first argument reflects variations in $Y$ across households that can be attributed to differences in observable household characteristics while the derivative of $m$ with respect to its second argument reflects variations in $Y$ across households of identical observable characteristics.

The parametric functional forms adopted for the different components of our income generation model imply a particular parametric shape for $m$,

$$
Y=m^{\xi}(X, \Upsilon ; \xi)
$$

where $m^{\xi}$ represents the parametric structure and $\xi$ is the vector of parameters. To be clear, Eq. 13 has no structural interpretation. It should be viewed as a set of reduced form equations linking individual and household characteristics to income-a relationship that may arise from an unspecified, broader structural model-through earnings functions, equations for employment and occupational and industrial structure, equations for non-labour income and replacement incomes and through tax-and-transfer rules. The distribution function $F-$ and therefore any index functional $\theta(F)$-depends on the (joint) distribution function of $X$ and $\Upsilon$ in the population through $m^{\xi}$ and $\xi$.

In this model, the distribution of income in two countries can differ because of differences in the distribution of $X$, in the joint distribution of normalised residuals $\Upsilon$ and differences in $m$. It is assumed that different countries can be represented by a common parametric model of the form $m^{\xi}$ but that countries differ in the values taken by the parameters $\xi$.

\subsection{Four Transformations of the Income Generation Process}

We define a number of transformations that, when applied to the model, allow us to capture how sensitive the income distribution is to specific dimensions of the model. We focus on four types of transformations that capture the relative contributions of four broad factors (or subsets thereof): (i) a labour market structure transformation, (ii) a price-and-returns transformation, (iii) a tax-benefit transformation and (iv) a demographic transformation.

The labour market structure transformation works through the parameter vector $\xi$. The transformation $\tilde{l}$ modifies the parameters of the equations characterizing the employment probabilities and hours worked $\left(\gamma^{l a b}, \gamma^{e m p}, \gamma^{h r s}\right)$, and the occupational and industrial structure $\left(\delta^{o c c}, \delta^{i n d}, \delta^{p u b}\right)$. When applied to a given income generation process, it leads to a 
transformed representation

$$
m^{\xi}(X, \Upsilon ; \tilde{l}(\xi))
$$

which implies a new counterfactual distribution of outcome $Y$ denoted $F^{l}$. The impact of the labour market structure transformation $m^{\xi}(X, \Upsilon ; \xi) \rightarrow m^{\xi}(X, \Upsilon ; \tilde{l}(\xi))$ on the functional $\theta$ is then given by $\Delta_{\theta}^{l}(F)=\theta\left(F^{l}\right)-\theta(F) . \Delta_{\theta}^{l}(F)$ measures how the index $\theta$ varies with the parameters describing the employment rate, the share of self-employment, and the occupation and industrial structure of employment (all conditional on household and individual characteristics) from the baseline $\xi$ to a counterfactual $\tilde{l}(\xi)$, leaving all other parameters and population characteristics unchanged. Note that the transformation of $\xi$ is not allowed to lead to variation in other parameters (notably wages) or in population characteristics. (We return to this in Section 5.)

The price-and returns transformation again acts through the parameter vector $\xi$. The transformation involves changing the parameters of the equations characterizing the level of earnings from employment and self-employment, $\left(\beta^{s e}, \sigma^{s e}\right)$ and $\left(\beta^{a, e m p}, \beta^{b, e m p}, \beta^{q, e m p}\right)$ and all other pre-tax incomes $\left(\left(\beta^{i n v}, \sigma^{i n v}\right), \quad\left(\beta^{\text {prop }}, \sigma^{\text {prop }}\right)\right.$, $\left.\left(\beta^{\text {pripen }}, \sigma^{\text {pripen }}\right),\left(\beta^{\text {other }}, \sigma^{\text {other }}\right)\right)$, leading to

$$
m^{\xi}(X, \Upsilon ; \tilde{r}(\xi))
$$

and $\Delta_{\theta}^{r}(F)=\theta\left(F^{r}\right)-\theta(F)$. This transformation is analogous, albeit in a multiple equations setup, to the manipulation of the vector of coefficients of Mincerian earnings regressions in order to capture 'price' effects (as distinct from 'composition effects) in traditional Oaxaca-Blinder decomposition exercises. It captures the influence of overall market returns to household characteristics. Note that, as in Juhn et al. (1993), the variance of the residuals is included as a "price" parameter.

Both the labour market structure and the price-and-returns transformations are variations in the parameter vectors and are therefore contingent on the particular specification adopted for $m^{\xi}$. A flexible set of equations avoids imposing excessive parametric restrictions and limits the risk of mis-specifying the relationship between characteristics $X$, residual heterogeneity $\Upsilon$ and household incomes. The specification of $m^{\xi}$ however inevitably involves a trade off between empirical tractability and flexibility; see Appendix A for details on the specification adopted here.

The third transformation is a tax-benefit transformation. The tax-benefit transformation is a particular transformation of the parameter vector $\xi$ which modifies (i) the parameters of the EUROMOD tax-benefit calculator which evaluate the tax liabilities and the level of benefits which are determined directly by EUROMOD, and (ii) the parameters determining the level of public transfers received by households that are not calculated by EUROMOD but modelled parametrically:

$$
m^{\xi}(X, \Upsilon ; \tilde{t} \vec{b}(\xi))
$$

(See Online Appendix $C$ for details on how the tax-benefit parameters can be modified in EUROMOD.) As above, we write the effect of a tax-benefit transformation on $\theta$ as $\Delta_{\theta}^{t b}(F)=\theta\left(F^{t b}\right)-\theta(F)$ where $F^{t b}$ denotes the distribution function of household incomes after the tax benefit transformation is applied to the income generation model. A tax-benefit transformation is, effectively, commonly applied in (static) microsimulation analysis of tax and benefit reforms when assessing the distributive impact of variations in policy parameters (see, e.g., Bargain and Callan 2010). Concerns about parametric restrictions are mitigated in the tax-benefit transformation since the micro-simulated components are derived from exact calculations based on explicit tax-benefit rules. Parametric restrictions remain in order only for the benefits which cannot be microsimulated, such as pensions. 
The fourth transformation is a demographic transformation. This is of a different nature in that it acts through modifying the distribution of population characteristics $X$, e.g., changing the share of households with high education, changing household size, etc.,

$$
m(\tilde{X}(X), \Upsilon ; \xi) \text {. }
$$

It leads to a counterfactual distribution of outcome $Y$ denoted $F^{d}$. The impact of the demographic transformation, $m^{\xi}(\tilde{X}(X), \Upsilon ; \xi)-m^{\xi}(X, \Upsilon ; \xi)$, on $\theta$ is given by $\Delta_{\theta}^{d}(F)=$ $\theta\left(F^{d}\right)-\theta(F) .^{5}$ In the context of an Oaxaca-Blinder decomposition, this would typically be coined the "explained" component, namely the part of the variation in the outcome that is accounted for by variations in the vector of characteristics, holding model parameters constant.

\subsection{Cross-country Comparisons: Transform-and-Transplant}

In cross-country comparisons, the four transformations can be calibrated so as to 'transplant' components of the income generation model across countries and to create counterfactuals $F^{A, k(B)}$ obtained by applying to country $A$ the transformation $k$ calibrated on country $B$ parameters. The impact of such a transplantation on index $\theta, D_{\theta}^{k}\left(F^{A}, F^{B}\right)=$ $\theta\left(F^{A, k(B)}\right)-\theta\left(F^{A}\right)$, quantifies the importance of the transplanted parameters in accounting for the difference in income distributions in the two countries.

The labour market structure transformation applied to country $A, \tilde{l}(\xi)$ involves the subset of parameters from $\xi^{A}$ for the fixed parameters and of parameters taken from $\xi^{B}$ for the transformed parameters which capture the characteristics of the labour market structure in the income generation model. The transformed income generation process for country $A$ thereby leads to a simulated distribution for country $A$ 'as if it had a labour market structure as country $B$ ' and all other components of the model remained unchanged. The difference between the simulated and the observed distributions in country $A$ (and inequality functionals defined over them) provides a quantification of the contribution of labour market structure differences to the overall difference in income distribution between the two countries. This is fully analogous to standard Oaxaca-Blinder decompositions-swapping regression coefficients across earnings equations for alternative groups-although it is implemented in a multiple equations model.

The transplantation of country $B$ parameters onto country $A$ 's model is done similarly for the price-and-returns transformation by swapping the relevant subset of parameters. Unlike the labour market structure transformation, the price-and-returns transformation involves swapping variance terms, $\sigma^{2}$. This is achieved as in Juhn et al. (1993) by rescaling the residuals of country $A$ by the ratio $\frac{\sigma_{S}}{\sigma_{A}^{S}}$ for each of the five components $S$ that are affected by the transformation. Note that this procedure scales the distribution of residual terms in each equation but preserves the rank correlation of residuals across the different equations of the income generation model. ${ }^{6}$

The calibration of the tax-benefit transformation combines both swapping model parameters as above (for the equations describing benefits) and using the EUROMOD tax-benefit calculator to apply the tax and benefit rules and parameters of country $B$ onto the market incomes and household characteristics of country $A$. This factor quantifies differences

\footnotetext{
${ }^{5}$ This measure is called a 'partial distributional policy effect' in Rothe (2012), or simply a 'policy effect' in Firpo et al. (2009)

${ }^{6}$ See Appendix A.3 for further details on the treatment of residuals.
} 
across countries in how market incomes are transformed into disposable income after taxbenefit policies are applied. EUROMOD makes it easy to implement 'policy swaps' in which particular tax or benefit policies from one reference country or year are applied to other countries or time periods. Such transplantation of tax-policy rules and parameters is most often done for analysis of trends in income distributions (see Bargain and Callan 2010, 2012; Herault and Azpitarte 2015; Paulus and Tasseva 2017), but it has also been applied to cross-country analysis (Levy et al. 2007). ${ }^{7}$

Finally, the demographic transformation involves modifying the distribution of population characteristics of country $A$ in such a way that it has the (joint) distribution of country $B$. This transformation examines the contribution of population differences to differences in the distribution of income across countries. The distribution of $X$ is modified but the conditional distribution of $\Upsilon$ given $X$ must not be affected to remain as it is in $A$. As shown in DiNardo et al. (1996) and Barsky et al. (2002), this can be achieved semi-parametrically by reweighting. In evaluating $F$ or $\theta(F)$, population $A$ households are reweighted by a factor

$$
\omega(X)=\frac{\operatorname{Pr}(X \mid B)}{\operatorname{Pr}(X \mid A)}=\frac{\operatorname{Pr}(B \mid X)}{\operatorname{Pr}(A \mid X)} \frac{\operatorname{Pr}(A)}{\operatorname{Pr}(B)} .
$$

The probabilities in Eq. 18 can be estimated by standard techniques for binary responses; see e.g., Biewen and Juhasz (2012) for a recent application of this approach.

To summarize, we now have four measures obtained by a 'transform-and-transplant' procedure, $D_{\theta}^{l}\left(F^{A}, F^{B}\right), D_{\theta}^{r}\left(F^{A}, F^{B}\right), D_{\theta}^{t b}\left(F^{A}, F^{B}\right)$, and $D_{\theta}^{d}\left(F^{A}, F^{B}\right)$, which quantify the impact of four distinct potential drivers of differences in income distributions in the parametric representation presented in Section 2.2. Their relative sizes help us figure out "what counts" in driving distributional differences across countries.

\subsection{Inequality Decomposition}

The proposed 'transform-and-transplant' procedure assesses the impact of each factor from the same initial benchmark distribution $A$ : the transformations are applied one at a time. As Biewen and Juhasz (2012) argue, comparison of such 'direct effects' is a natural way to compare the effects of alternative transformations.

The sum of these 'direct effects' however does not add up to the total difference in inequality. First, the model and the transformations are non-linear, so the sum of the direct effects, $\sum_{k \in\{d, r, l, t b\}} D_{\theta}^{k}\left(F^{A}, F^{B}\right)$, is not equal to the composition of the four transformations, $D_{\theta}^{T o t}\left(F^{A}, F^{B}\right)$, obtained by applying all four transformations together, $m^{\xi}(\tilde{X}(X), \Upsilon ; \tilde{t b} \circ \tilde{r} \circ \tilde{l}(\xi)) .{ }^{8}$ Second, the four transformations do not address all possible sources of cross-country differences arising from the income generation process. Notably the (joint) distribution of normalised residuals $\Upsilon$ is left as in benchmark country $A$. We did not define specific transformations involving the residual terms as these do not have clearcut economic interpretations: they mainly reflect the correlation of scaled residuals across

\footnotetext{
${ }^{7}$ In an intertemporal context, studies usually attempt to disentangle the contribution of structural changes in policies from the mere uprating of policy parameters defined in nominal monetary units (Bargain 2012; Figari et al. 2015). The issue is less relevant in the present context and we swap both structural differences and nominal parameters at once. For the conversion of nominal parameters across countries, all monetary units expressed in different currencies are converted on the basis of exchange rates in the year concerned.

${ }^{8}$ An alternative quantification of the four factors is to examine their marginal impact in a sequence of composed transformations. While this leads to an additive decomposition, the measures depend on the composition sequence (or path-dependence) (Biewen 2014).
} 
all income sources, but also cross-country differences in residual distributions that may be due to unmodelled heteroscedasticity or model misspecification.

If one seeks to additively decompose the overall difference in $\theta$ between countries $A$ and $B$ on the basis of the transform-and-transplant approach, two additional terms need to be introduced to account for the distribution of residual terms and the higher order interactions across transformations:

$$
\begin{aligned}
\Delta_{\theta}\left(F^{A}, F^{B}\right)= & \theta\left(F^{B}\right)-\theta\left(F^{A}\right) \\
= & D_{\theta}^{l}\left(F^{A}, F^{B}\right)+D_{\theta}^{r}\left(F^{A}, F^{B}\right)+D_{\theta}^{t b}\left(F^{A}, F^{B}\right)+D_{\theta}^{d}\left(F^{A}, F^{B}\right) \\
& +D_{\theta}^{\Upsilon}\left(F^{A}, F^{B}\right) \\
& +I_{\theta}\left(F^{A}, F^{B}\right)
\end{aligned}
$$

where (i) the term $D_{\theta}^{\Upsilon}\left(F^{A}, F^{B}\right)$ reflects the contribution of differences in the distribution of normalised residuals $\Upsilon,{ }^{9}$ and (ii) the term $I_{\theta}\left(F^{A}, F^{B}\right)=\Delta_{\theta}\left(F^{A}, F^{B}\right)-$ $\sum_{k \in\{r, l, t b, d, \Upsilon\}} D_{\theta}^{k}\left(F^{A}, F^{B}\right)$ captures all two-way and three-way interactions between the direct components of the model and is equal to the difference between the total difference in $\theta$ and the sum of direct effects (Biewen 2014).

\section{Application to Ireland and the United Kingdom}

We now provide an application of the methods to Ireland and the United Kingdom. The two countries share a common language and border and have much in common, historically and with respect to labour market and Welfare State policies which were influenced by similar political philosophy principles. Nonetheless, the income distributions in the two countries differ quite substantially. In 2007, the last year before the financial crisis hit both countries, the Gini coefficient was 0.28 in Ireland-a relatively low figure by international standards-while it was 0.32 in the UK-among the highest EU figure. To put the gap in perspective, a difference of four Gini points corresponds to the increase in disposable income inequality reported by OECD (2011) for the USA between the mid-1980s and the late 2000's - a period during which inequality is thought to have increased dramatically.

\subsection{Data}

We exploit two nationally representative household surveys: the European Union Statistics of Income and Living Conditions (EU-SILC) for Ireland and the Family Resources Survey (FRS) for the United Kingdom. These surveys contain detailed information about household incomes as well as a wide range of variables about the characteristics of households and their members. They have been the key sources of official statistics about the distribution of income in both countries.

A central component of our model is the tax-benefit microsimulation engine EUROMOD, so we use the "EUROMOD input data" versions of the FRS and EU-SILC datasets which have been standardized to common definitions for (market) income variables and

\footnotetext{
${ }^{9} D_{\theta}^{\Upsilon}\left(F^{A}, F^{B}\right)$ is obtained by transplanting residuals across countries. This is achieved, in reverse, by starting from country $B$ and jointly applying all four transformations calibrated to country $A$ parameters. The difference between this construct and country $A$ 's orginal distribution reflects the 'direct' effect of transplanting residuals from $A$ to $B$.
} 
household characteristics by the EUROMOD team (Sutherland and Figari 2013). The definition of disposable household income in EUROMOD includes the sum across all household members of market incomes and public pensions plus cash benefit minus taxes and social insurance contributions. Note that cash benefits and taxes are not reported by survey respondents but are calculated by the tax-benefit calculator. This assumes away any tax evasion and assumes full take-up of benefits. Income distribution statistics based on market incomes with microsimulated taxes and benefits usually exhibit lower inequality and poverty than statistics based on disposable incomes directly reported survey respondents (Bargain et al., 2017, Figari et al., 2015). Microsimulated incomes tend to be higher at the bottom of the distribution than reported incomes, partly because of the full take-up assumption and partly because of reduced under-reported and measurement error. Reassuringly however, validation studies from EUROMOD country reports for Ireland and the UK show that the ratio between the microsimulated and reported Gini coefficient is almost identical in the two countries at 0.89 in the UK and 0.90 in Ireland in the year we examine (Sutherland et al. 2012; Keane et al. 2012). ${ }^{10}$

We study the distribution of income in 2007 in both countries and incomes are expressed in 'single adult equivalent' by dividing total household income by the square root of household size. Currency values for the UK are converted in euros using the exchange rate of 1.484 British pounds per euro. Samples sizes are 12,516 individuals (5,247 households) in the Irish data and 57,276 individuals (25,088 households) in the UK sample.

\subsection{Inequality in Ireland and the UK Compared}

The distributions of income in the two countries are shown in Fig. 1 in the form of Pen's parades (quantile functions divided by mean income). The vertical axis is on a logarithmic scale: a vertical shift of the curves corresponds to a proportional increase of all incomes-a transformation that leaves most commonly-used inequality measures unchanged. Overall, the UK displays a steeper profile, especially above the 50th percentile. Until the 80th percentile, incomes (relative to the mean) are higher in Ireland than in the UK whereas incomes of the richest $20 \%$ are higher in the UK relative to the country mean-see the bottom panel. These differences translate into a higher inequality in the UK than in Ireland as measured by the Gini index (see Table 1). Figure 2 shows Lorenz dominance of the Irish distribution over the UK distribution so the country ranking in inequality is robust to the choice of inequality index.

Table 2 shows differences across the two countries in a number of population characteristics and labour market structures in the FRS and EU-SILC datasets. The two countries have similar demographic profiles; with some notable exceptions however. According to our samples, the population aged 25-64 is generally more educated in Ireland than in the UK, and there are larger shares of people aged $65+$ and smaller shares of children aged $4+$ in the UK than in Ireland. The share of people aged 16+ at work is 6 percentage points higher in Ireland than in the UK but their distribution across occupations are similar. The distribution of workers across sectors of activity is however remarkably different: the share of workers in agriculture is almost four times larger in Ireland than in the UK, the share in industry

\footnotetext{
${ }^{10}$ In some countries, EUROMOD offers the option to apply a correction to the data so as to match external statistics on take-up proportions (Sutherland and Figari 2013). The correction consists in randomly imputing 'non take-up' and therefore assigning zero benefits to a fraction of the sample households. This is done separately for different sources of benefits. This option is switched off when full take-up is assumed.
} 

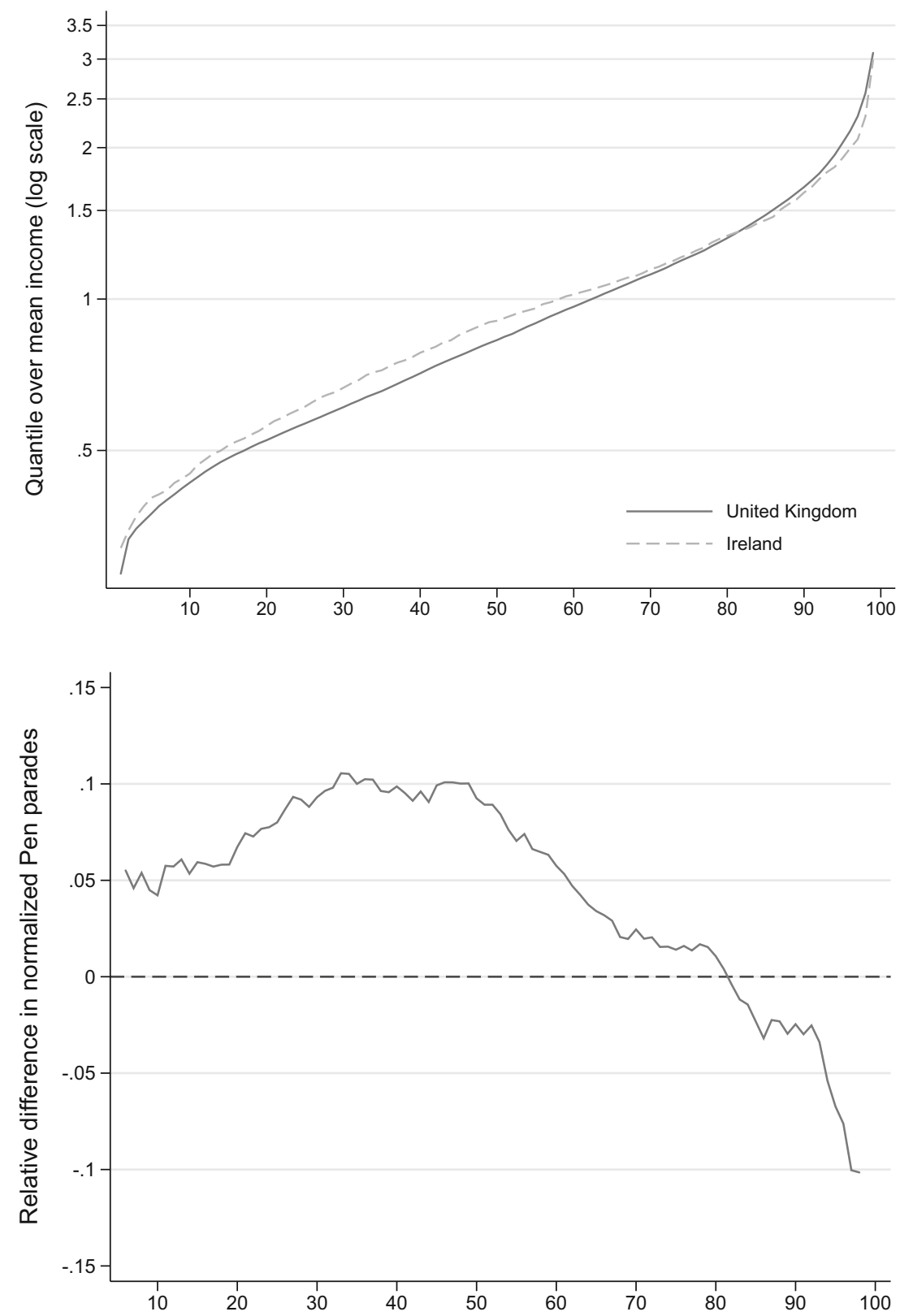

Fig. 1 Distribution of equivalized household disposable income in Ireland and the UK: Normalized quantile functions (Pen's parades) (top) and relative differences (IE-UK/UK) (bottom)

is less than half, and the services sector employs 10 percentage points more people in Ireland. Public sector employment is also larger in the UK. Table 2 also points to differences in the household income composition. The prevalence of non-labour income sources dif- 
Table 1 Equivalized household disposable income in the UK and Ireland, 2007 (monthly, in euros)

\begin{tabular}{llll}
\hline & Mean & Median & Gini \\
\hline UK & 2341 & 1940 & 0.319 \\
Ireland & 2541 & 2300 & 0.277 \\
\hline
\end{tabular}

fers between the two countries, with the UK exhibiting larger shares of people with private pensions, capital and other sources of income.

Both the Irish and UK tax-benefit systems are part of the Anglo-Liberal system of Welfare States. With mainly flat rate or means-tested benefit instruments, the primary objective of the transfer system is poverty alleviation. While there are differences, many of the historical developments in the Irish benefit system have derived from reforms in the UK system. Both are characterized by (i) flat rate and means-tested income replacement benefits (the main difference rests in the presence of a previous earnings related component in the UK system, that although contemplated at various stages in Ireland was never introduced); (ii) in-work transfers (both countries have transfers targeted at low-income families with children, where payments are made once a particular number of hours have been made; there is an additional child care component in the UK system); (iii) flat rate universal child benefits and child tax credits; and (iv) housing benefits (coverage has been lower historically in Ireland, but has been increasing).

Both countries have progressive income taxation and earnings-related social insurance contributions that vary for employees and the self-employed. The Irish income taxation system is joint, while the UK system is an individualized system. Table 3 documents the redistributive effects of the tax-benefit system in both countries. Inequality in market income

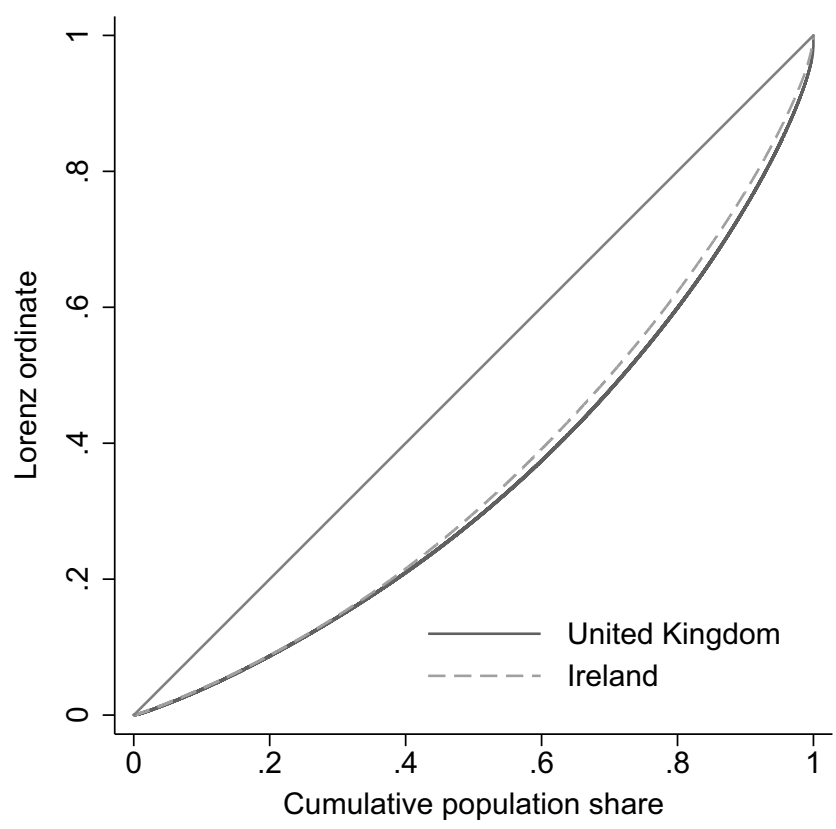

Fig. 2 Lorenz curves for the United Kingdom and Ireland 
Table 2 Population and labour market structures (shares of total population)

UK Ireland

Demographic

\begin{tabular}{llr}
\hline Tertiary Education & 0.263 & 0.314 \\
People 16-65 & 0.667 & 0.676 \\
People ¿65 & 0.146 & 0.102 \\
Child 0-3 & 0.052 & 0.051 \\
Child 4-11 & 0.087 & 0.108 \\
Child 12-15 & 0.048 & 0.063 \\
Married & 0.504 & 0.485 \\
Citizen & 0.906 & 0.927 \\
Male & 0.486 & 0.496
\end{tabular}

Labour market

In-work $\quad 0.557$

0.619

Employee

0.883

0.864

Occupation

Managers

0.158

0.174

Professionals

0.285

0.232

Clerks

0.119

0.115

Service

0.153

0.180

Craft

0.113

0.162

Plant

0.072

0.045

Unskilled

0.101

0.092

Industry

Agriculture

0.014

0.048

Industry

0.218

0.087

Services

0.769

0.865

Public/Private

0.283

0.234

Other market factors

With private pensions

0.342

0.146

With capital income

0.576

0.214

With other income

0.099

0.052

Notes: The estimates are weighted. The shares for education refer to age-group 25-64; for married, sex to age $>=16$; for in-work to ages 16 to 80 ; for employees, occupation, industry and sector to those in work aged $[16,80)$. The shares for citizen refer to individuals holding the citizenship as proportion of the entire sample. The shares for private pensions refer to ages $>=45$, for capital age $>=16$

is more similar in the two countries than inequality of disposable income. The benefit schedule increases the difference in inequality between the two countries by dropping inequality to a larger extent in Ireland compared with the UK, an effect driven by a higher degree of redistribution in Ireland. The benefit schedule is more regressive in the UK (more low incomes receive benefits), but the average benefit rate is also much lower. The tax system 
Table 3 Progressivity and redistribution of taxes and benefits on household equivalized disposable income

\begin{tabular}{llll}
\hline & UK & Ireland & Ratio: IRL/UK \\
\hline Gini Gross Income & 0.497 & 0.483 & 0.972 \\
Gini Gross Income (incl. benefits) & 0.377 & 0.341 & 0.905 \\
Averate transfer rate & 0.155 & 0.242 & 1.558 \\
Benefit Regressivity (K) & 0.936 & 0.769 & 0.822 \\
Benefit Redistribution (RS) & 0.120 & 0.142 & 1.184 \\
Gini (gross + benefits - income taxes) & 0.332 & 0.289 & 0.871 \\
Averate tax rate & 0.159 & 0.132 & 0.826 \\
Tax Progressivity (K) & 0.242 & 0.354 & 1.460 \\
Tax Redistribution (RS) & 0.045 & 0.053 & 1.156 \\
Gini Disposable Income & 0.319 & 0.277 & 0.869 \\
Net Redistributive Effect & 0.178 & 0.206 & 1.157 \\
\hline
\end{tabular}

Notes: $\mathrm{K}=$ Kakwani; $\mathrm{RS}=$ Reynolds-Smolensky

further increases the percentage point difference in inequality between Ireland and the UK. This is due to a more progressive and a more redistributive tax system in Ireland. As taxes are progressive and benefits are regressive, the net schedule is equalizing in both countries. The Reynolds-Smolensky index of net redistributive effect shows the Irish tax-benefit system is more redistributive than the UK system (Lambert 2001). Whether these differences are due to policy design or to differences in the market income distribution is revealed in the decomposition analysis.

\subsection{Accounting for differences in income inequality}

Preliminary inspection of the characteristics of the population and the income distribution suggests the difference in income inequality may stem from the variations in the tax-benefit system, as well as the industry structure and the distribution of the non-market income sources. Applying the counterfactual decomposition quantifies the respective roles played by such factors.

\subsubsection{Counterfactual distributions}

A decomposition of the differences between the mean-normalized quantile functions of the two distributions of equivalised disposable income is displayed in Fig. $3 .{ }^{11}$ Remember that mean-normalized quantiles are higher in Ireland than in the UK up to the 80th quantile beyond which the difference turns negative; the observed difference is marked by dots on the plot. The counterfactual differences obtained by applying each of the four transformations defined in Section 3 onto the UK data are shown in Fig. 3. Figure 3a shows the total, observed difference; Fig. 3b, c, d and e show how the 'first order', direct effect of applying each of the four transformations compares to the total difference; Fig. $3 \mathrm{f}$ highlights the unexplained and interaction terms.

\footnotetext{
${ }^{11}$ The set of parameter estimates and their standard errors for all regression equations of the income generation model are reported in Appendix F (available online).
} 


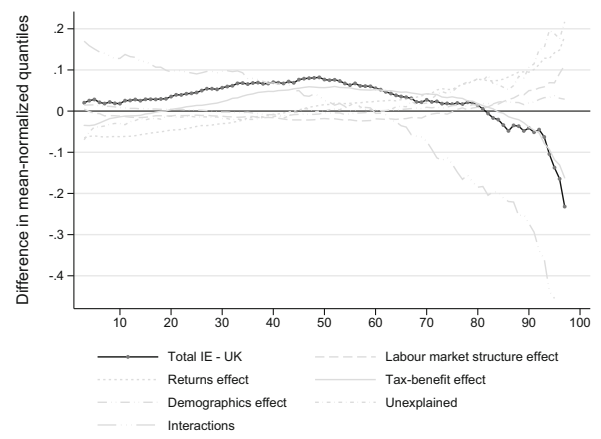

(a) Total

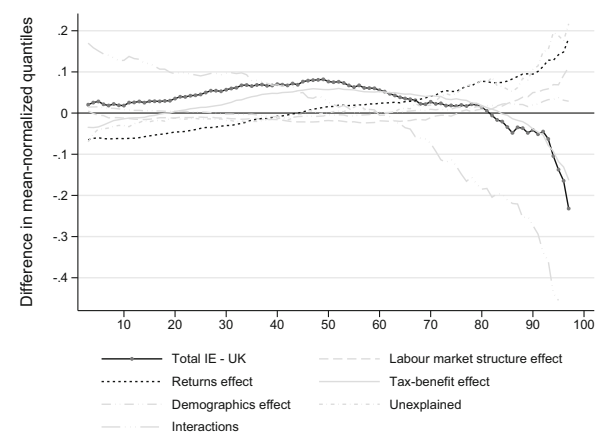

(c) Price and Returns

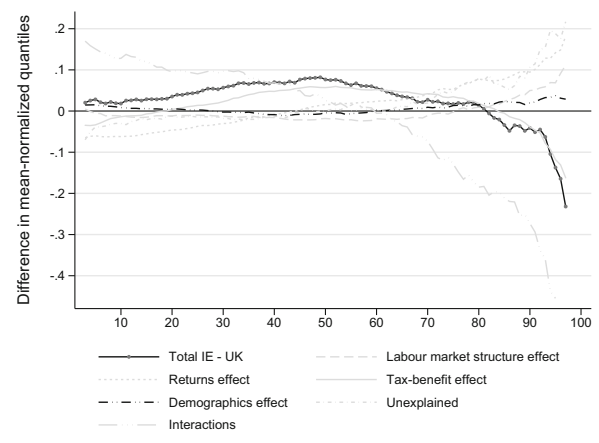

(e) Demographics

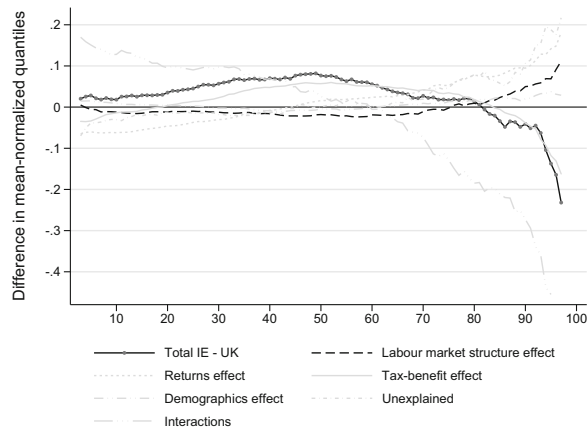

(b) Labour Market Structure

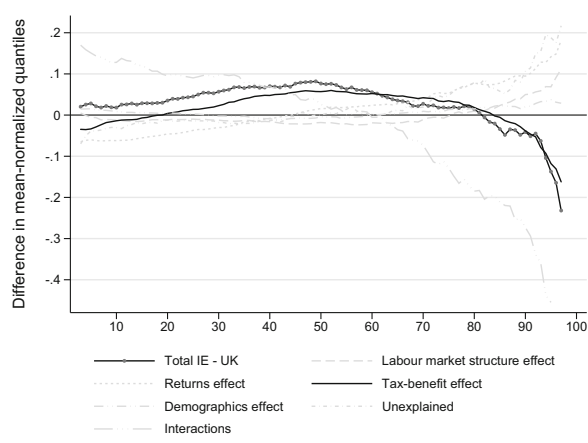

(d) Taxes and Benefits

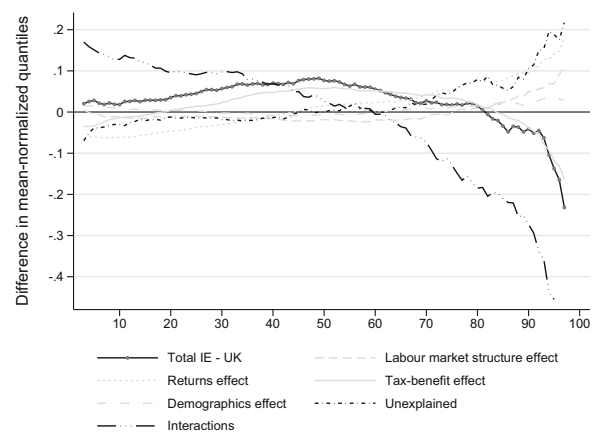

(f) Interactions and unexplained

Fig. 3 Distributional differences across quantiles of equivalized household disposable income and counterfactuals after labour market structure transplant, prices and returns transplant, taxes and benefits transplant, demographic transplant, and resulting interactions and residual terms

One key observation comes from the tax-benefit transformation (highlighted in panel (d)). Applying the Irish tax-benefit rules onto the UK data generates a counterfactual difference to the UK distribution that is remarkably close to the actual difference between Ireland and the UK. The match is particularly close for incomes above the median. For the bottom half of the distribution, tax-benefit differences do not appear to fully explain the higher values observed in Ireland. As the tax-benefit effect is basically a policy effect (net of differences in the market income distributions between the two countries), these results point to 
differences in social and fiscal policies as the most important determinant of income distribution differences between the two countries. The negative tax-benefit effect for the bottom and top $20 \%$ indicates that the UK tax-benefit rules are more advantageous to the poorest and the richest households than the Irish rules. Overall, this is consistent with a higher benefit regressivity of the UK system and a higher tax progressivity of the Irish system.

The transformation having the second strongest impact is the price-and-returns transformation. However its impact mostly works against the observed difference. Applying the Irish structure of returns to demographic and labour market characteristics onto the UK data would tend to reduce the incomes of the bottom 40 percent and increase incomes for the top 60 percent-overall a "disequalizing effect". The counterfactual quantile function is nowhere close to the actual difference observed between the two countries (except to the point where the two curves cross around the 65th percentile). A similar lesson is drawn from the labour market structure transformation: applying the employment rate, the occupational and industrial characteristics of Irish employment, and the prevalence of non-market incomes in Ireland onto the UK population also works against the observed difference. It leads to slightly lower incomes throughout the bottom 75 percent of the population and larger incomes for the top 25 percent. This pattern can be tracked to the higher employment rate and the larger shares of workers in the service and agricultural sectors, and the lower prevalence of non-labour incomes found in Ireland. The demographic transformation has the smallest impact of all. Applying the Irish demographic characteristics onto the UK population only leads to a modest increase of income for the top 20 percent. This pattern is consistent with the higher share of tertiary educated and "prime age" individuals in Ireland documented in Table 2, but it also discards demographic differences as the source of the greater inequality observed in the UK.

The picture that emerges is one where the Irish tax-benefit system "undoes" what otherwise appear to be disequalizing factors in the Irish labour market structure and in the returns to characteristics in terms of market income, compared to the UK.

Interactions are inherent to the non-linear transformations applied to the income distributions (Biewen 2014). For example we apply the Irish tax-benefit transformation directly on the UK distribution of market incomes and population structure. But if we had applied the tax-benefit transformation on a "modified" UK distribution reflecting the "disequalizing" adjustments due to the population structure or the different returns to characteristics, we can expect that its impact would have been stronger than shown in Fig. 3. These interactions beyond the "first order" effect of the transformations are bundled into the interaction term. The multiplicative interactions between the transformations are reflected in the last panel of Fig. 3. The interaction between the tax-benefit system, the labour market, returns and demographic structures is relatively large.

The magnitude of the effect of the residual differences is similar in magnitude and direction to the labour market and returns transformation, working against the observed difference. One possible explanation for the larger residual effect at the top is the correlation of income sources in the households (including partners earnings) which is not modelled and "swapped" in our counterfactuals. The correlation of incomes is difficult to model parametrically and is therefore left in the residual term.

\subsubsection{Gini coefficients of disposable and market incomes and the net redistributive impact of taxes and transfers}

We move to examination of Gini indices. The first column of Table 4 presents decomposition results for the difference in the Gini coefficients of disposable income-a 0.042 


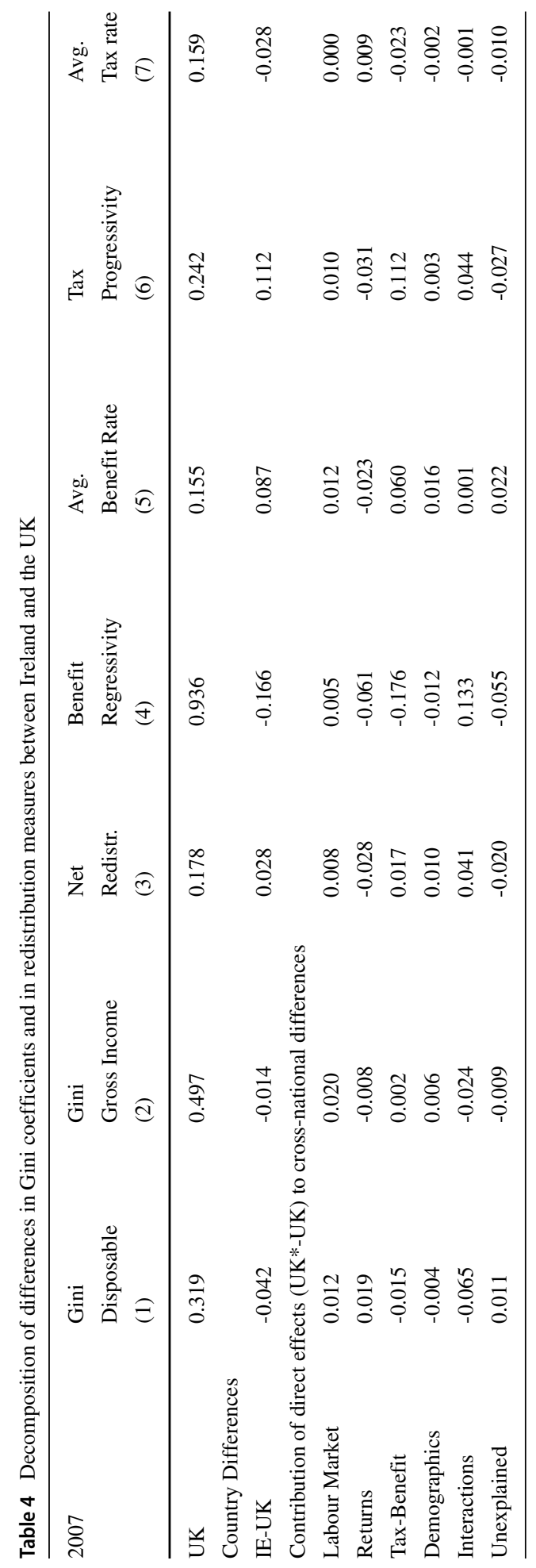


difference between 0.319 in the UK and 0.277 in Ireland (rows 1-2). Rows 3-6 show the direct effects of applying each of our four transformations onto the UK distribution: the difference between the Gini coefficient in the counterfactual distribution that would prevail in the UK if we transplant each factor in isolation from Ireland and the original distribution. Rows 7 and 8 capture respectively the interaction effects (which sum all the two, three and four-way interactions between the four factors) and the role of residuals difference. The direct effect of differences in the two tax-benefit systems $(-0.015)$ is over one third of the observed difference in disposable income inequality (-0.042). As was already apparent from Fig. 3, the cross-country difference in disposable income inequality appears largely attributable to differences in tax-benefit systems which counterbalance the disequalizing effect of the differences in market composition and returns between Ireland and the UK.

The difference in gross income inequality between the two countries (column 2) is smaller than in disposable income, yet inequality remains smaller in Ireland. Gross income includes labour market income, private pensions, capital and "other" pre-tax incomes. Gross income inequality would be higher in the UK had the UK the market composition of Ireland but it would be lower if the Irish returns to assets and human capital where transplanted in the UK. Again, the contribution of demographic differences is comparatively small. ${ }^{12}$

In order to evaluate the sampling error of the estimated effects, we apply a grouped jackknife variance estimator (Shao and $\mathrm{Tu}$ 1995) that allows us to obtain standard errors for complex, non-linear statistics while keeping computational tractability. The households are divided into $m$ groups of size $g$. The statistic of interest, $T_{n-g, i}$ is re-computed based on data with the $i$-th group removed, and after $m$ evaluations, the grouped variance estimator is $v_{G J A C K}=\frac{m-1}{m} \sum_{i=1}^{m}\left(T_{n-g, i}-\frac{1}{m} \sum_{j=1}^{m} T_{n-g, j}\right)^{2}$. We set $m=10$. Confidence intervals are calculated assuming asymptotic normality based on this grouped jackknife variance estimator. The effects and their confidence intervals are illustrated in Fig. 4. Confidence intervals are reassuringly small; our analysis appears to have enough power to provide statistically significant results in spite of its size and the number of parameters involved. Confidence intervals are smallest for the tax-benefit transformations. This is commonly found in decomposition exercises with a deterministic tax-benefit model ( $\mathrm{Li}$ et al. 2020; Paulus and Tasseva 2017). In our case, the tax-benefit simulations mainly rely on a deterministic EUROMOD tax-benefit calculator and only partly on regression-based models (for partially and non-simulated variables required in each country model). ${ }^{13}$

The difference between the Gini coefficient for gross incomes and for net disposable incomes is a standard measure of the net redistributive effect of taxes and transfers. The net redistribution through taxes and transfers appears larger in Ireland than in the UK (see column 3 in Table 4). However such measures of net redistribution are the result of the combination of a country's tax-benefit system applied to its own distribution of gross incomes and are therefore difficult to compare across countries. When comparing the redistributive features of different tax-benefit systems, one should evaluate them against the same distri-

\footnotetext{
${ }^{12}$ The small effect of the taxes and benefits transformation on gross income inequality is due to adjustments to minimum wages which are included in the taxes and benefit transformation.

${ }^{13}$ On a related note, a reviewer observed that the larger impact found for the tax-benefit factor compared to the labour market structure and price and returns components may also be related to this difference in treatment. The effect of components based on swapping regression parameters are more likely to be absorbed by the residuals effect if the regression models have low explanatory power or if the models are misspecified, and the tax-benefit transformation components is less likely to be misspecified. While we cannot address this formally, we note that treating residual variances as part of the parameters swapped across countries limits this concern.
} 


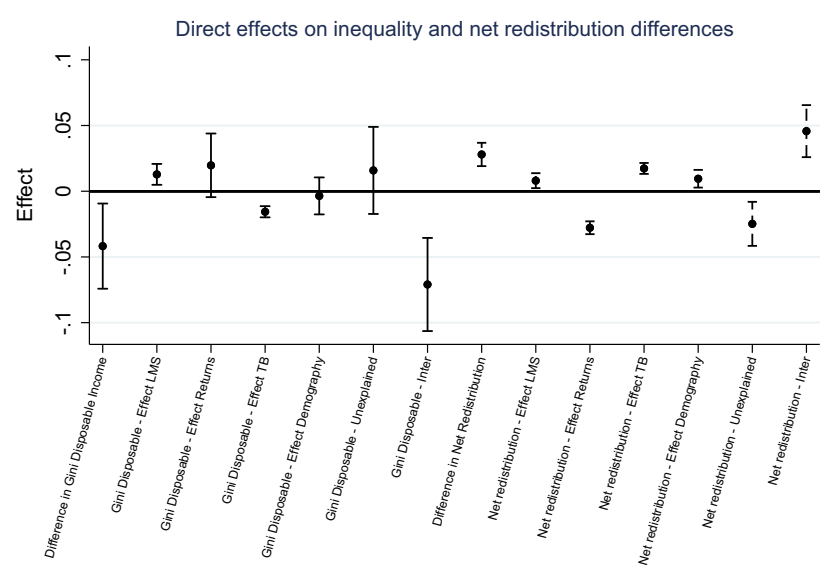

(a)

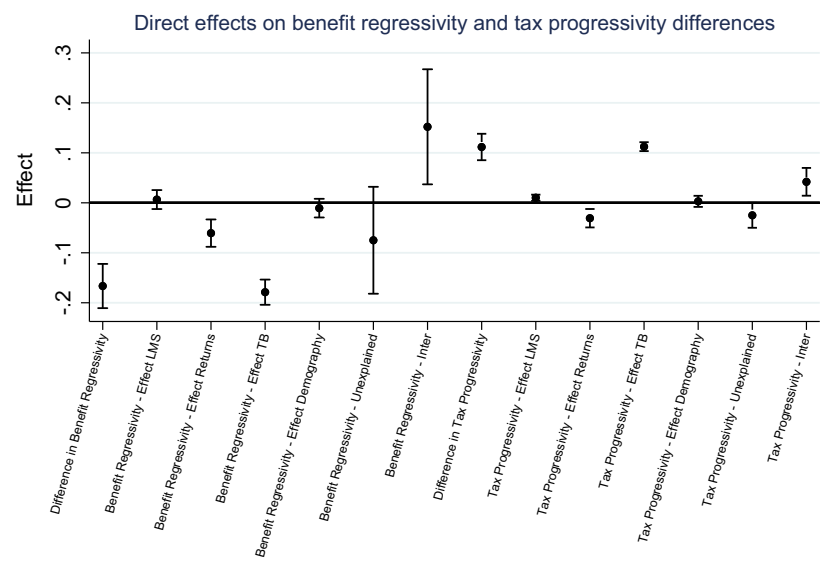

(b)

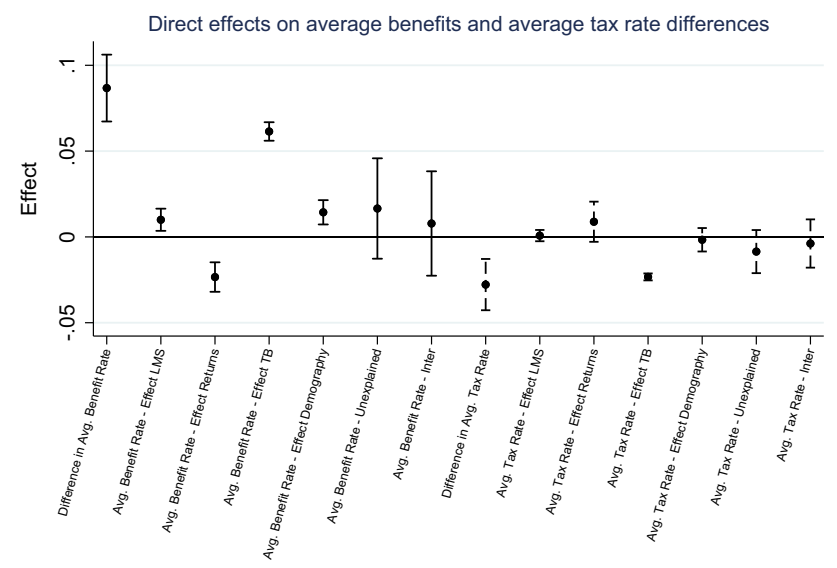

(c)

Fig. 4 Direct Effects, Interaction and Residual Terms with Grouped Jackknife Confidence Intervals 
bution of gross incomes. Existing studies comparing different tax-benefit rules, however, do not control for differences in gross income distributions, therefore the effects are difficult to compare across countries (see, e.g., Verbist and Figari 2014). We can exploit our decomposition framework to examine, first, to what extent the differences in net redistributive effects of the two countries is due to policy design and how much is due to differences in gross incomes between the two countries. Second, we can assess how much the different model components account for the overall redistributive effect of taxes and transfers. It turns out that over $60 \%$ of the total difference in net redistributive effect is accounted for by differences in tax and benefit parameters (as captured by application of the taxesand-benefits transformation, col. 3). By design, the Irish the system is more redistributive than its UK counterpart, but the Irish lead in redistribution is eroded partially by differences in gross income distributions. Columns 4-7 of Table 4 detail the channels through which this happens by examining the progressivity/regressivity of benefits (col. 4), taxes (col. 6), the average benefit-to-income ratio (col. 5) and average tax rates (col. 7). The Irish taxbenefit system appears to be more redistributive than the UK system because of a higher tax progressivity and larger average benefits rates. The UK system has a higher benefits regressivity and lower average tax rates. Even when measured on identical market income distributions (that is, after transplanting the Irish TB system on the UK data), tax progressivity and average benefit rates, and overall net redistribution are larger under the Irish tax-benefit system. By design, the Irish tax schedule is more progressive and the Irish benefits are more generous than the UK counterparts. The difference in average benefit rates due solely to policy differences is lower (6 percentage points) than the observed difference (8.7 percentage points), suggesting that market income difference leads to a greater difference in the average benefit rates between the two countries.

Table 5 shows the contribution of more disaggregated transformations. For the sake of brevity, we do not detail the construction of all those sub-transformations but they should be self-explanatory from the table labels and notes: they involve swapping only a subset of model parameters from 'labour market structure' and 'price and returns' transformations across countries (either parameters reflecting the returns to some specific characteristics or reflecting the relative prevalence of such characteristics). The effect of the labour market structure transformation is mostly driven by differences in the prevalence of non-labour incomes in household portfolios. The price and returns transformation impact on disposable income mostly arises from the parameters of the non-labour incomes equations again (concerning mostly capital incomes) while equations for labour income and private pensions are driving the impact of the transformation on gross incomes.

\section{Incorporating Labour Supply Adjustments}

Having estimated a set of static counterfactuals, we now allow for behavioural adjustments in the simulations. The optimal tax literature has long recognized the importance of accounting for labour supply responses to tax changes (Mirrlees 1971) and recent analysis of tax-benefit policy changes incorporate analysis of labour supply responses to estimate the full effect of a reform (see, e.g., Aaberge et al. 1995; Bargain 2012).

While the counterfactual distributions that we construct are primarily meant to quantify the contribution of various factors to inequality differences across countries in a static perspective-we are not trying to describe accurately what would actually happen in country $A$ if, say, its labour market structure was to morph suddenly into the structure of $B$ (this would 
Table 5 Decomposition of differences in Gini coefficients: disaggregation of the transformations

\begin{tabular}{lll}
\hline 2007 & Gini & Gini \\
& Disposable & Gross Income \\
\hline UK & 0.319 & 0.497 \\
Country Differences & & -0.014 \\
IE-UK & -0.042 & 0.020 \\
Contributions to cross-national differences (UK*-UK) & \\
Labour Market Structure & 0.012 & -0.013 \\
Labour Market Structure Components & & 0.005 \\
In-work & -0.001 & -0.004 \\
Employed/Self-employed & 0.004 & 0.036 \\
Occupation/Industry/Sector & -0.007 & 0.000 \\
Has non-labour income & 0.013 & -0.003 \\
Other & 0.004 & -0.008 \\
Interactions & -0.001 & \\
Returns & 0.019 & 0.001 \\
Returns Components & & -0.006 \\
Labour Income & -0.001 & -0.011 \\
Private Pensions & 0.004 & 0.007 \\
Capital and Other Income & -0.000 & \\
Interactions & 0.016 & \\
\hline & & \\
\hline
\end{tabular}

require a full structural model of labour market adjustment, occupational choices, education, fertility, household formation, etc.)—we can incorporate a structural labour supply model which adjusts employment probabilities (including part-time employment) by household members as a function of the household demographic characteristics and disposable income where disposable income is itself a function of tax-benefit parameters, wages and non-labour incomes and individual characteristics. We describe in Appendix B, the integration of a labour supply model identifying household labour supply elasticities that allows us to adjust employment probabilities as a result of either changes in tax-benefit parameters (after a tax-benefit transformation) or changes in market incomes following from a price-and-return or labour market structure transformation.

The addition of the labour supply response alters the sequence of the simulation compared with what was described in Section 2. Unemployment, non-participation, and working hours are now jointly simulated instead of sequentially determined. The logic for the rest of the simulation remains unchanged. Comparing the decomposition results with and without allowing for labour supply adjustments to our cross-country transformations informs us of the potential importance of understanding behavioural responses (at least in the short run). We isolate below the contribution of labour supply responses by taking the difference between the counterfactual distribution when labour supply responses are considered and the completely "static" counterfactual. The cumulative effect of the "swap" is decomposed into a direct effect and indirect effect from the labour supply response.

We do not attempt to account for behavioural responses other than the labour supply change due to the disposable income change. It is entirely possible that, e.g., tax and benefit 


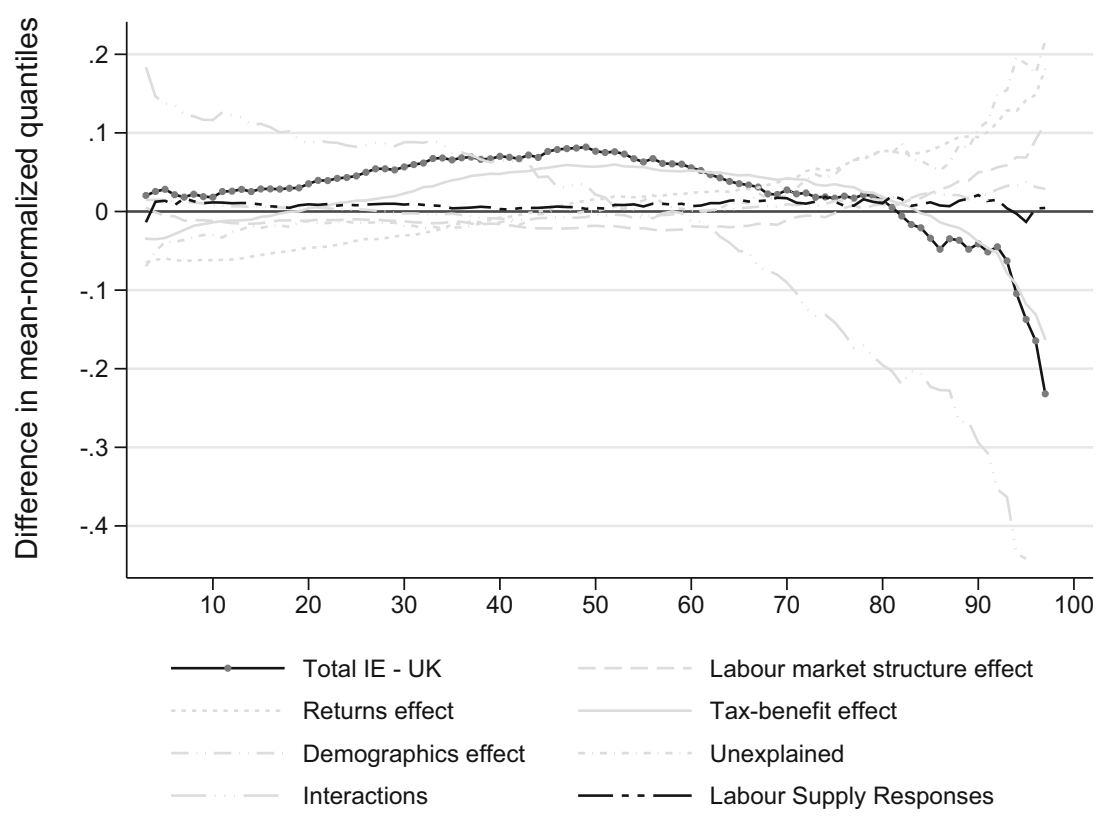

Fig. 5 Incorporating Labour Supply Responses

system change would also induce shifts in consumption and saving patterns. Fertility, education and retirement decisions may also be affected by changes in the tax and benefit system or labour market parameters. Allowing for such complex behavioural adjustments is beyond the scope of the present exercise and focus on the simpler isolation of the short-term labour supply impacts of the notional cross-country policy and labour market transplantations.

When labour supply responses are considered, the impact of each transformation on distribution functionals $\theta$ is composed of a direct effect and an indirect effect incorporating the labour supply response. The first term reflects the change in $\theta$ implied by the transformations (as described in Section 3) and the second term reflects the change in $\theta$ implied by the change in household employment triggered by the transformations. The contribution to cross-country differences in $\theta$ of the labour supply adjustment to transformation $k$ equals the difference between the counterfactual obtained with a labour supply adjustment to transformation $k$ and the counterfactual without a labour supply response (as presented earlier): $L S_{\theta}^{k}\left(F^{A}, F^{B}\right)=\theta\left(F^{A, k l s(B)}\right)-\theta\left(F^{A, k(B)}\right)$. The total effect of transformation $k$ is then the sum of the earlier direct effect $D_{\theta}^{k}(F)$ and $L S_{\theta}^{k}\left(F^{A}, F^{B}\right)$. The overall inequality difference is now decomposed as

$$
\begin{aligned}
\Delta_{\theta}\left(F^{A}, F^{B}\right)= & D_{\theta}^{d}\left(F^{A}, F^{B}\right)+D_{\theta}^{l}\left(F^{A}, F^{B}\right)+D_{\theta}^{r}\left(F^{A}, F^{B}\right)+D_{\theta}^{t b}\left(F^{A}, F^{B}\right) \\
& +L S_{\theta}^{l}\left(F^{A}, F^{B}\right)+L S_{\theta}^{r}\left(F^{A}, F^{B}\right)+L S_{\theta}^{t b}\left(F^{A}, F^{B}\right) \\
& +D_{\theta}^{\Upsilon}\left(F^{A}, F^{B}\right)+I_{\theta}\left(F^{A}, F^{B}\right)
\end{aligned}
$$

where the interaction effect is now net of labour supply behavioural responses. Note that there is no labour supply adjustment term for the demographic transformation because, by construction, such a transformation does not lead to any change in our household labour supply predictions (it does not lead to any change in relevant individual or household-level variables). 


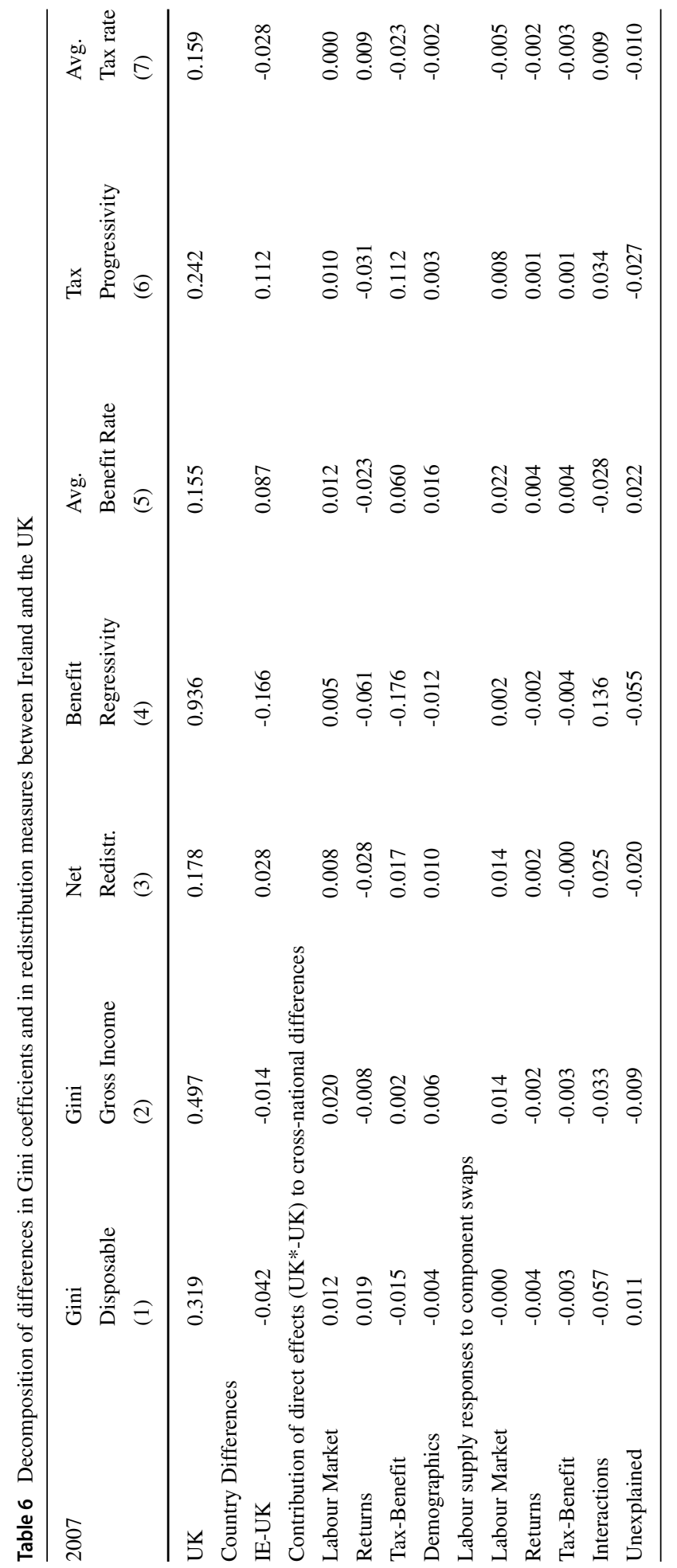


Estimates of the three labour supply adjustment terms are reported in Fig. 5 (all three effects combined) and Table $6 .{ }^{14}$ Figure 5 reports the decomposition results when endogenous labour supply is introduced in the estimation. The labour supply model captures the labour supply preference of the population, allowing us to swap the incentive structure of the economic system while retaining both the observed population characteristics and unobserved preferences to some extent. To avoid cluttered lines in Figure 5, we only plot the overall labour supply effect. Compared with Figure 3, the labour supply adjustment mitigates the direct effects of the labour market transformation. The adjustment, however, is relatively minor for each component as reported in Table 6. For most components, the behavioural adjustment is slightly larger at the higher end of the income spectrum where the absolute income differences between the UK and Ireland are the largest. The overall results suggest the labour supply behavioural change is a minor indirect factor in comparison with the direct transformations.

\section{Concluding Remarks}

This paper develops a methodological framework for exploring the drivers of cross-national differences in the distribution of household disposable income, focusing on the role of taxbenefit systems, labour market structures, prices and returns, and demographic structures. Our framework draws upon the Bourguignon et al. (2008) methodology by developing a household income distribution which incorporates a flexible parametric approach of modelling wage differentials across the entire distribution. We incorporate tax-benefit rules through micro-simulation (EUROMOD) and discuss how potential labour supply responses can be incorporated in the generation of counterfactual distributions. The result is an integrated framework that is portable across EU countries for generating and simulating the distribution of household disposable income under alternative scenarios, thereby enabling the study of the various drivers of the cross-national distributional differences in household disposable income. The framework proposed is descriptive by nature and, while there are trade-offs between tractability and realism, the apparatus offers sufficient sophistication to allow detailed analysis of the way tax-benefit systems can interact with labour market structures, income structures and demographics in determining the distribution of household disposable income and in explaining cross-national differences in disposable income inequality. Compared to alternative decomposition approaches such as Oaxaca-Blinder, and some variance decomposition techniques for inequality indices, the method can better capture the effects of policy, labour market, income and demographic structures through simulated counterfactuals. On the policy side, this method allows the comparison of the redistributive effects of different designs of tax-benefit rules while controlling for market income differences. It allows assessing to what extent the observed differences in inequality between countries is due to differences in policy design.

The paper illustrates use of the method through the analysis of two European neighbouring English-speaking countries-the UK and Ireland-that share many similarities while displaying at the same time sufficient differences to merit examination of the factors that have resulted in different levels of inequality. We explored the drivers of distributional differences between these countries in 2007, the last year before the economic crisis in both

\footnotetext{
${ }^{14}$ Due to the time-intensive computation involved, we do not report standard errors for the decomposition terms adjusted for labour supply responses.
} 
countries. Whereas market income distribution is roughly 1.4 Gini point less unequal in Ireland than in the UK, the difference in inequality in disposable income is almost three times higher (4.2 Gini points). Our decomposition analysis reveals that over one third of the difference across countries in inequality in disposable income is due to policy parameter differences, which offset half of the disequalizing contributions of labour market structures and returns. The magnitudes of the three effects are comparable in absolute terms. Differences in demographic characteristics of the two populations (including differences in educational attainment), however, play a negligible role. When we control for market income differences, we confirm that, by design, the Irish tax-benefit system is more redistributive than the UK system due to a higher tax progressivity and more generous average transfer rates.

We conclude with a word of caution. Albeit more flexible than what has been used in related research about the determinants of cross-country differences in inequality, our approach remains largely parametric. Our estimates of the role of the four main drivers examined are contingent on the income generation process and on the parametric mappings adopted. Our results hinge on the parametric representation to provide a good fit to the data in the two countries compared. Inspection of the goodness-of-fit of our aggregate predictions is reassuring, but in the absence of reliable non-parametric estimates for all the conditional distributions composing the income generation model (given the sample sizes at hand), we cannot formally test our parametric models for misspecification. Future research exploiting non-parametric approaches in larger, possibly administrative, data should hopefully allow relaxing parametric assumptions.

Acknowledgments This research is part of the SimDeco project (Tax-benefit systems, employment structures and cross-country differences in income inequality in Europe: a micro-simulation approach) supported by the National Research Fund, Luxembourg (grant C13/SC/5937475). Emilia Toczydlowska and Carina Toussaint provided invaluable research assistance. The results presented here use EUROMOD version G2.0+. EUROMOD is maintained, developed and managed by the Institute for Social and Economic Research (ISER) at the University of Essex, in collaboration with national teams from the EU member states. We are indebted to the many people who have contributed to the development of EUROMOD. The process of extending and updating EUROMOD is financially supported by the European Union Programme for Employment and Social Innovation 'Easi' (2014-2020). The results and their interpretation are our responsibility. We are grateful for comments from Francesco Andreoli and Stephen Jenkins and from participants to the International Microsimulation Association conferences 2015 and 2017, the "Inequality in the Labour Market 2015" workshop , APPAM 2016, ECINEQ 2017, EALE 2017, and the SimDeco workshop 2017 on "Understanding international differences in income inequality".

Open Access This article is licensed under a Creative Commons Attribution 4.0 International License, which permits use, sharing, adaptation, distribution and reproduction in any medium or format, as long as you give appropriate credit to the original author(s) and the source, provide a link to the Creative Commons licence, and indicate if changes were made. The images or other third party material in this article are included in the article's Creative Commons licence, unless indicated otherwise in a credit line to the material. If material is not included in the article's Creative Commons licence and your intended use is not permitted by statutory regulation or exceeds the permitted use, you will need to obtain permission directly from the copyright holder. To view a copy of this licence, visit http://creativecommonshorg/licenses/by/4.0/.

\section{References}

Aaberge, R., Dagsvik, J.K., Strøm, S.: Labor supply responses and welfare effects of tax reforms. Scand. J. Econ. 97(4), 635-659 (1995)

Agresti, A.: Analysis of Ordinal Categorical Data. Wiley Series in Probability and Statistics. Wiley, New York (2010) 
Alesina, A., Glaeser, E.: Fighting Poverty in the U.S. and Europe: A World of Difference. Oxford University Press (2005)

Atkinson, A.B.: The distribution of earnings in OECD countries. Int. Labour Rev. 146(1-2), 41-60 (2007)

Bargain, O.: Back to the future: decomposition analysis of distributive policies using behavioural simulations. Int. Tax Publ. Financ. 19(5), 708-731 (2012)

Bargain, O., Callan, T.: Analysing the effects of tax-benefit reforms on income distribution: a decomposition approach. J. Econ. Inequal. 8(1), 1-21 (2010)

Barsky, R., Bound, J., Charles, K., Lupton, J.: Accounting for the black-white wealth gap: a nonparametric approach. J. Am. Stat. Assoc. 97, 663-673 (2002)

Belfield, C., Blundell, R., Cribb, J., Hood, A., Joyce, R.: Two decades of income inequality in Britain: The role of wages, household earnings and redistribution. Economica 84(334), 157-179 (2017)

Biewen, M., Jenkins, S.P.: A framework for the decomposition of poverty differences with an application to poverty differences between countries. Empir. Econ. 30(2), 331-358 (2005)

Biewen, M.: Additive decompositions and interaction effects. Appl. Econ. Lett. 21(9), 636-642 (2014)

Biewen, M., Juhasz, A.: Understanding rising income inequality in Germany, 1999/2000-2005/2006. Rev. Income Wealth 58(4), 622-647 (2012)

Bourguignon, F., Ferreira, F., Lustig, N.: The Microeconomics of Income Distribution Dynamics in East Asia and Latin America. The World Bank (2005)

Bourguignon, F., Ferreira, F.H., Leite, P.G.: Beyond Oaxaca-Blinder: Accounting for differences in household income distributions. J. Econ. Inequal. 6(2), 117-148 (2008)

Brandolini, A., Smeeding, T., Nolan, B.S.T.: Income Inequality in Richer and OECD Countries. In: Salverda, W. (ed.) The Oxford Handbook of Economics Inequality, chapter Income Inequality in Richer and OECD Countries, pp. 71-100. Oxford University Press (2010)

Brewer, M., Wren-Lewis, L.: Accounting for changes in income inequality: Decomposition analyses for the UK, 1978-2008. Oxf. Bull. Econ. Stat. 78(3), 289-322 (2016)

Colombino, U., Locatelli, M., Narazani, E., O’Donoghue, C., et al.: Alternative basic income mechanisms: an evaluation exercise with a microeconometric model. Basic Income Stud. 5(1), 1932-0183 (2010)

Cowell, F.A., Flachaire, E., Bandyopadhyay, S.: Goodness-of-fit: An economic approach. Distributional Analysis Discussion Paper, (101) (2009)

Cowell, F., Fiorio, C.: Inequality decompositions-a reconciliation. J. Econ. Inequal. 9(4), 509-528 (2011)

Creedy, J., Duncan, A.: Behavioural microsimulation with labour supply responses. J. Econ. Surv. 16(1), 1-39 (2002)

Daly, M.C., Valletta, R.G.: Inequality and poverty in United States: The effects of rising dispersion of men's earnings and changing family behaviour. Economica 73(289), 75-98 (2006)

DiNardo, J., Fortin, N.M., Lemieux, T.: Labor market institutions and the distribution of wages, 1973-1992: a semiparametric approach. Econometrica 64(5), 1001-1044 (1996)

Ebert, U.: Measures of distance between income distributions. J. Econ. Theory (32), 266-274 (1984)

Eurostat: Gini coefficient of equivalised disposable income - EU-SILC survey, European Commission, http:// ec.europa.eu/eurostat/web/products-datasets/-/tessi190, (accessed June 12 2017) (2017)

Figari, F., Paulus, A., Sutherland, H.: Microsimulation and policy analysis. In: Atkinson, A.B., Bourguignon, F. (eds.) Handbook of Income Distribution, volume 2B, chapter 24, pp. 2141-2221, North-Holland (2015)

Firpo, S., Fortin, N.M., Lemieux, T.: Unconditional quantile regressions. Econometrica 77(3), 953-973 (2009)

Förster, M., Tóth, I.G.: Cross-country evidence of the multiple causes of inequality changes in the OECD area. In: Atkinson, A.B., Bourguignon, F. (eds.) Handbook of Income Distribution, volume 2B, chapter 19, pp. 1729-1843, North Holland (2015)

Fortin, N., Lemieux, T., Firpo, S.: Decomposition methods. In: Ashenfelter, O., Card, D. (eds.) Handbook of Labor Economics, vol. 4A, pp. 1-102. Amsterdam, North-Holland (2011)

Haveman, R., Heinrich, C., Smeeding, T.: Policy responses to the recent poor performance of the U.S. Labor market. J. Policy Anal. Manage. 31(1), 153-195 (2011)

Herault, N., Azpitarte, F.: Understanding changes in the distribution and redistribution of income: a unifying decomposition framework. Rev. Income Wealth 62, 266-282 (2015)

Hyslop, D.R., Mare, D.C.: Understanding New Zealand's Changing Income Distribution, 1983 - 1998: A Semi-parametric Analysis. Economica 72(287), 469-495 (2005)

Jenkins, S., Brandolini, A., Micklewright, J., Nolan, B. (eds.): The Great Recession and the Distribution of Household Income. Oxford University Press, Oxford (2013)

Juhn, C., Murphy, K.M., Pierce, B.: Wage inequality and the rise in returns to skill. J. Polit. Econ. 101(3), 410-442 (1993)

Keane, C., Elish, K., Callan, T., Savage, M.: Euromod country report, pp. 2006-2011, Ireland (2012) 
Keane, M., Moffitt, R.: A structural model of multiple welfare program participation and labor supply. Int. Econ. Rev. 39(3), 553-589 (1998)

Lambert, P.J.: The Distribution and Redistribution of Income. Manchester University Press, Manchester (2001)

Larrimore, J.: Accounting for United States household income inequality trends: The changing importance of household structure and male and female labor earnings inequality. Rev. Income Wealth 60(4), 683-701 (2014)

Lerman, R.I., Yitzhaki, S.: Income inequality effects by income. Rev. Econ. Stat. 67(1), 151-156 (1985)

Levy, H., Lietz, C., Sutherland, H.: Swapping policies: Alternative tax-benefit strategies to support children in Austria, Spain and the UK. J. Soc. Policy 36(4), 625-647 (2007)

Li, J., La, H.A., Sologon, D.M.: Policy, demography, and market income volatility: What shaped income distribution and inequality in Australia between 2002 and 2016? Review of Income and Wealth (2020)

Matzkin, R.L.: Nonparametric estimation of nonadditive random functions. Econometrica 71(5), 1339-1375 (2003)

Mirrlees, J.A.: An exploration in the theory of optimum income taxation. Rev. Econ. Stud. 38(2), 175-208 (1971)

Nolan, B., Salverda, W., Checchi, D., Marx, I., McKnight, A., Tóth, I.G., van de Werfhorst, H.G. (eds.): Changing Inequalities and Societal Impacts in Rich Countries: Thirty Countries' Experiences. Oxford University Press, Oxford (2014)

O’Donoghue, C.: Practical Microsimulation Modelling. Oxford University Press, Oxford (2019)

OECD: Divided We Stand: Why Inequality Keeps Rising. OECD, Paris (2011)

Paulus, A., Tasseva, I.: Decomposition of Changes in the EU Income Distribution in 2007-2011. EUROMOD Working Paper EM 9/17, Institute for Social and Economic Research. University of Essex, UK (2017)

Piketty, T.: Capital in the Twenty-First Century. Harvard University Press, Cambridge (2013)

Rothe, C.: Nonparametric estimation of distributional policy effects. J. Econ. 155(1), 56-70 (2010)

Rothe, C.: Partial distributional policy effects. Econometrica 80(5), 2269-2301 (2012)

Shao, J., Tu, D.: The Jackknife and Bootstrap. Springer, Berlin (1995)

Shorrocks, A.: The class of additively decomposable inequality measures. Econometrica 48, 613-625 (1980)

Shorrocks, A.F.: Inequality decomposition by factor components. Econometrica 50(1), 193-211 (1982)

Sologon, D.M., Van Kerm, P., Li, J., O'Donoghue, C.: Accounting for differences in income inequality across countries: Ireland and the United Kingdom. LISER Working Papers, (2018-01) (2018)

Sutherland, H., Figari, F.: EUROMOD: The European Union tax-benefit microsimulation model. Int. J. Microsimul. 6(1), 4-26 (2013)

Sutherland, H., Tumino, A., Zantomio, F.: Euromod country report, pp. 2006-2011, UK (2012)

Van Kerm, P.: Generalized measures of wage differentials. Empir. Econ. 45(1), 465-482 (2013)

Van Kerm, P., Choe, C., Yu, S.: Decomposing quantile wage gaps: a conditional likelihood approach. J. R. Stat. Soc. (Ser. C) 65(4), 507-527 (2016)

Van Soest, A.: Structural models of family labor supply: A discrete choice approach. J. Human Resour. 30(1), 63-88 (1995)

Van Soest, A., Das, M., Gong, X.: A structural labour supply model with flexible preferences. J. Econ. 107(1-2), 345-374 (2002)

Verbist, G., Figari, F.: The redistributive effect and progressivity of taxes revisited: An international comparison across the European Union. FinanzArchiv: Publ. Finance. Anal. 70(3), 405-429 (2014)

Publisher's note Springer Nature remains neutral with regard to jurisdictional claims in published maps and institutional affiliations. 


\section{Affiliations}

\section{Denisa M. Sologon ${ }^{1}$ (D) . Philippe Van Kerm ${ }^{1,2} \cdot$ Jinjing $\mathrm{Li}^{3} \cdot$ Cathal O'Donoghue}

Philippe Van Kerm

philippe.vankerm@liser.lu

Jinjing Li

jinjing.li@canberra.edu.au

Cathal O'Donoghue

cathal.odonoghue@nuigalway.ie

1 Luxembourg Institute of Socio-Economic Research, Esch-sur-Alzette, Luxembourg

2 University of Luxembourg, Esch-sur-Alzette, Luxembourg

3 NATSEM, Institute for Governance and Policy Analysis, University of Canberra, Bruce, Australia

4 The National University of Ireland, Galway, Ireland 